\title{
LESS IS MORE: THE IMPACT OF MINDFULNESS MEDITATION ON UNDERGRADUATE STUDENTS' ACADEMIC PERFORMANCE
}

\author{
C. $\mathrm{Coo}^{1}$, J. Escartin ${ }^{2}$ \\ ${ }^{1}$ Universitat Jaume I (SPAIN) \\ ${ }^{2}$ Universitat de Barcelona (SPAIN)
}

\begin{abstract}
Mindfulness in higher education has become a popular subject in academic research. Several studies have shown the positive effects of mindfulness practice for undergraduate students, lowering anxiety levels, improving self-esteem and promoting social skills. Despite this interest, the evidence suggesting all these positive effects translate into improved academic performance is still scarce.

Aim: The aim of the study was to analyze the influence of mindfulness practice on academic performance of 302 students of the degree of Psychology at the University of Barcelona (Spain) utilizing a control group. Method: The students were distributed between two conditions: the first condition underwent mindfulness practice during the first 10 minutes of class during ten weeks of the academic year; the second condition underwent no practice at all. As well, both conditions were split in two equal size groups. Academic performance was measured trough mean grade score at the end of the academic year. Results: The results confirmed that students who attended mindfulness practices achieved better academic performance compared to those who did not attend practice sessions.
\end{abstract}

Conclusions: The study's findings suggest that mindfulness is a successful strategy to improve academic performance in undergraduate students. It is an innovative and easy practice to implement that has a positive impact on overall student learning experience. The underlying psychological mechanisms that explain the effects of mindfulness practice on academic performance remains to be explored.

Keywords: mindfulness, organizational psychology, academic performance, student satisfaction, wellbeing.

\section{INTRODUCTION}

Mindfulness represents a field of growing interest in a multitude of different disciplines, among them psychology, where it has been conceptualized as a mean to cultivate awareness about the experiences we live in each and every present moment [1]. The practice of mindfulness implies the cultivation of an unprejudiced perspective (towards oneself and others) [2], therefore it allows one to leave unpleasant thoughts behind, instead of ruminating on them, and accept the world as it is [3]. Utilizing a colloquial and prosaic language, Siegel [4] has defined mindfulness as "waking up from a life lived in autopilot and becoming sensitive to the novelty available in our daily lives".

One of the major virtues of mindfulness that the educational context has discovered is the fact that it is easy to implement and practice. Even though the most popular standardized mindfulness practice program consists in eight weeks of training [5], its positive effects are evident even after a brief practice [6]. Mindfulness based interventions are low cost, easy to implement and highly efficacious. Mindfulness has been proven to be an effective tool for improving the capacity to deal with stressful tasks [7], decision making [8], and cognitive performance [9] thanks to a better cognitive flexibility and attentional functioning [10].

Inspired by McCloskey [11] who recently emphasized that "little attention has been paid to the potential benefits of mindfulness in relation to the improvement of academic performance", the general objective of this study is to analyse the impact of mindfulness practice on the academic performance of undergraduate students.

\subsection{Benefits of mindfulness on academic performance}

Growing empirical evidence suggest that students that practice mindfulness achieve better scores in standardized tests y university exams [11]. Cranson, Orme, David, y Gackenbach [12] reported better learning capabilities in a sample of undergraduate students from the USA who practiced mindfulness 
twice a day. Docksai [13] recently conducted a study in the USA to determine if mindfulness helped students prepare for exams. Results indicated that students who participated of mindfulness exercises performed better than those who didn't. As well, Leon [14] reported a positive relation between mindfulness and academic performance in sample of secondary students in Spain.

\section{METHODOLOGY}

\subsection{Participants}

The participants of the study consisted in 302 undergraduate students $(76,5 \%$ women, mean age 21.36, $S D=1.20$ ) from the 4 ht year in the degree of Psychology at the University of Barcelona, Spain. The students were divided in four distinct academic groups.

\subsection{Materials and Procedure}

The study is based in the inter-subject aggrupation variable between two distinct conditions: Mindfulness practice group and control group. For each one of these conditions there were two groups. For the mindfulness practice condition groups 3 and 4 were utilized. For the control condition groups 1 and 2 were utilized. The students distributed among the four distinct groups all had the same teacher and the same time schedule during the academic year.

Regarding the data gathering procedure. Mean scores of the whole academic year grades were taken as academic performance rating. Ranging from 0 to 10 ( 0 - "non-sufficient" and 10 - "excellent"). $\mathrm{Al}$ grades were given by the courses teacher.

\subsection{Design}

Along the academic year the students were invited to dedicate 10 minutes before class start to a mindfulness exercise guided by the teacher. The exercises were always voluntary and those who desired so could wait outside the classroom or arrive after the conclusion of the exercise.

\section{RESULTS}

The first objective of this study was to discern if the mean scores by the end of the academic year were similar or not between the four groups and two conditions (control and mindfulness). Comparing the mean scores of group 1 and 2 control we obtained a Student's $t=1.77$ (155), $p=.08$. And between groups 3 and 4 (mindfulness) we obtained a Student's $t=-1.05$ (147), $p=.30$. Therefore, no differences were detected in the two comparisons, that is, there were no significant differences between the groups that didn't practice mindfulness and those who did.

The second objective was to compare the different conditions. Group 1 was compared with groups 3 and 4 (mindfulness). Group 2 was compared with this two groups as well. Significant differences were observed between groups 1 and 3 (Student's $t=-4.74$ (160); $p<.001$ ), 1 and 4 (Student's $t=-5.68$ (157); $p<.001$ ), and between groups 2 and 3 (Student's $t=-2.49$ (145); $p<.01$ ) and 2 and 4 (Student's $t$ $=-3.37(142) ; p<.001)$.

\section{CONCLUSIONS}

The results showed how the academic performance was very similar among the two groups that did not practice mindfulness. As well, academic performance was similar between the two groups of students who did practice mindfulness. When comparing the different conditions in a total of four possible interactions (group 1 against 3 and 4; and group 2 against 3 and 4) differences were detected. This results resonate with other findings in similar studies conducted in other countries, like USA, where mindfulness practice had a positive impact in academic performance [15].

\section{REFERENCES}

[1] J. Kabat-Zinn, Wherever you go there you are: Mindfulness meditation in everyday life. New York/NY: Hyperion, 1994. 
[2] S.L. Shapiro, L.E. Carlson. The art and science of mindfulness: Integrating mindfulness into psychology and the helping professions. New York/NY: APA publications, 2009.

[3] J.P. Phelan. "Friendliness to the self", Mindfulness, 3, 165-173., 2012.

[4] R.D. Siegel. The Mindful Therapist: A Clinician's Guide to Mindsight and Neural Integration. New York/NY: WW Norton \& Co., 2010.

[5] J. Kabat-Zinn, Mindfulness-based practices in context: Past, present, and future. Clinical Psychology: Science and Practice, 10, 144-158., 2003.

[6] J.D. Creswell, M.R. Irwin, L.J. Burklund, et al. Mindfulness-based stress reduction training reduces loneliness and pro-inflammatory gene expression in older adults: a small randomized controlled trial. Brain Behavior and Immunity, 26, 1095-101., 2012.

[7] G. Feldman, E. Dunn, C. Stemke, K. Bell, J. Greeson. Mindfulness and rumination as predictors of persistence with a distress tolerance task. Personality and Individual Differences, 56, 154168., 2014.

[8] S. Sun, Z. Yao, J. Wei, R. Yu. Calm and smart? A selective review of meditation effects on decision making. Frontiers in Psychology, 6, 1059, 1-11., 2015.

[9] T. Gard, B.K. Hölzel, W.S. Lazar. The potential effects of meditation on age-related cognitive decline: a systematic review. Ann N Y Acad Sci, 1307, 89-103., 2014.

[10] H.S. Hodgins, K.C. Adair. Attentional processes and meditation. Consciousness and Cognition, 19, 872-878., 2010

[11] L.E. McCloskey. Mindfulness as an Intervention for Improving Academic Success among Students with Executive Functioning Disorders. Procedia - Social and Behavioral Sciences, 174(12), 221-226., 2015.

[12] R.W. Cranson, J. Orme, W. David, J. Gackenbach. Transcendental meditation and improved performance on intelligence- related measures: A longitudinal study. Personality \& Individual Differences, 10, 1105-1116., 1991.

[13] R. Dockasi. A mindful approach to learning. The futurist, 47(5), 8-10., 2010.

[14] B. León. Atención plena y rendimiento académico en estudiantes de enseñanza secundaria. European Journal of Education and Psychology, 1(3), 17-26., 2008.

[15] E. Rosenstreich. Mindfulness and Memory. In: Singh NN, Ed. Psychology of Meditation. New York: Nova; pp. 167-185., 2014. 